\title{
COMPARATIVE PHYSICAL BEHAVIOR OF SOUTHERLY BOUNDARY-LAYER WIND JETS
}

\author{
WALTER H. HOECKER \\ U.S. Weather Bureau, Washington, D.C. \\ ABSTRACT
}

\begin{abstract}
Wind data from the central five stations of the 1961 Weather Bureau boundary-layer-jet research pibal line are space-averaged as point data. In this form the information is compatible with other boundary-layer wind analyses made from composites of several points. Particular attention is paid to diurnal changes of jet speed, to Richardson numbers, and to inertial oscillations. Comparisons relative to the above items are made with two serial-data jet systems, as well as with theoretical models, and some similarities are found. Relationships among the jet, the geostrophic wind, and thermal wind are shown. The hodograph patterns for a jet with a surface inversion differ markedly from a jet imbedded in a temperature lapse. A certain combination of currently forecastable meteorological variables seems to be optimal for the development of the jet after sunset.
\end{abstract}

\section{INTRODUCTION}

In an earlier paper [5] the detailed time and space characteristics of three southerly boundary-layer jet systems, over the Western Plains between Amarillo, Tex., and Little Rock, Ark., were described by means of hourly isotach cross-sections. Since most previous jet analyses were performed with point data or were space averages of several adjacent points, [1] and [8] for example, data from the five special pibal research stations centered on Oklahoma City were space-averaged so that comparisons could be made with previous analyses. The portions of the pibal observational line selected had the advantage of being in the most persistent jet region for the cases examined and had the Oklahoma City RAOB station at the center.

By way of explanation, the three cases selected were the only ones, from a total of five observations, for which low-level southerly jets developed. Because of the small number of observations, it would seem that time averages would not be practicable. The representativeness of the conditions producing the jets, and that of the jets themselves, is not known. Theory, particularly Wexler's [9], predicts that a boundary-layer jet will form when the Bermuda High extends westward into the Southern Plains and provides air flow from southerly latitudes into the south-central United States. Jets were found to exist for all three observations with southerly flow more or less as theory predicted. The Weather Bureau's National Severe Storms Project, which operated the research pibal line, selected the dates for the observations, on the basis of criteria suggested by the late Dr. Harry Wexler.

Since the terrain around Oklahoma City is quite smooth, observations from the four stations in the rough-country region from Little Rock to Fort Smith were also analyzed to reveal contrasts between the jet characteristics over rough country and over smooth plains.
TABLE 1.-Special pibal network stations, code designations, and locations

\begin{tabular}{|c|c|c|c|c|c|c|}
\hline Station & Code & & Lor & ition & & Elevation \\
\hline $\begin{array}{l}\text { A marillo, Tex } \\
\text { Alanreed, Tex } \\
\text { Erick, Ok la } \\
\text { Dill City, Okla. } \\
\text { Hinton Junction, Okla } \\
\text { Oklahona City, Okla. } \\
\text { Shawnee, Okla, } \\
\text { Okemah, Okla } \\
\text { Warner, Okla } \\
\text { Fort Smith, Ark, } \\
\text { Blue Mountain, Ark } \\
\text { Fourche Junction, Ark } \\
\text { Little Rock, Ark, }\end{array}$ & $\begin{array}{l}\text { AMA } \\
\text { ALN } \\
\text { ERK } \\
\text { DCY } \\
\text { HIIJ } \\
\text { OKC } \\
\text { SHW } \\
\text { OKE } \\
\text { WAR } \\
\text { FSMT } \\
\text { BMT } \\
\text { FRJ } \\
\text { LIT }\end{array}$ & $\begin{array}{r}0 \\
35 \\
35 \\
35 \\
35 \\
35 \\
35 \\
35 \\
35 \\
35 \\
35 \\
35 \\
34 \\
34\end{array}$ & $\begin{array}{l}' N . \\
14 \\
13 \\
13 \\
17.5 \\
32 \\
24 \\
22 \\
26 \\
30 \\
20 \\
07 \\
51.5 \\
44\end{array}$ & $\begin{array}{r}\circ \\
101 \\
100 \\
99 \\
99 \\
98 \\
97 \\
96 \\
96 \\
95 \\
94 \\
93 \\
93 \\
92\end{array}$ & $\begin{array}{l}\text { 'W. } \\
42 \\
44 \\
53 \\
08 \\
21 \\
36 \\
56 \\
19 \\
17 \\
22 \\
42.5 \\
09 \\
14\end{array}$ & $\begin{array}{r}1,098 \\
910 \\
631 \\
576 \\
454 \\
392 \\
331 \\
275 \\
175 \\
141 \\
129.5 \\
134 \\
81\end{array}$ \\
\hline
\end{tabular}

The locations of the observation stations are shown in figure 1, and the stations are identified in table 1 . The topography in Arkansas is obviously rougher than it is in central Oklahoma.

\section{WIND DISTRIBUTION IN THE VERTICAL}

Graphs of wind speed distribution with height were constructed for the three cases under study to reveal the time changes of the wind profiles. An interval of $2 \mathrm{hr}$. between graphs was estimated to be close enough to secure essential details. Individual case discussions follow.

APRIL 22-23, 1961

The average vertical wind speed structure for the approximately middle one-third of the pibal line (average of 5 simultaneous pibal runs) for the observational period $1600 \mathrm{cST}$, April 22 to $1400 \mathrm{csT}$, April 23, 1961, is shown for every $2 \mathrm{hr}$. in figure 2 . Thick lines are total wind speed while thin lines represent the southerly components. Where the lines merge the southerly component is the total wind. The southerly components are included to represent the southerly-component jets described in [5]. 


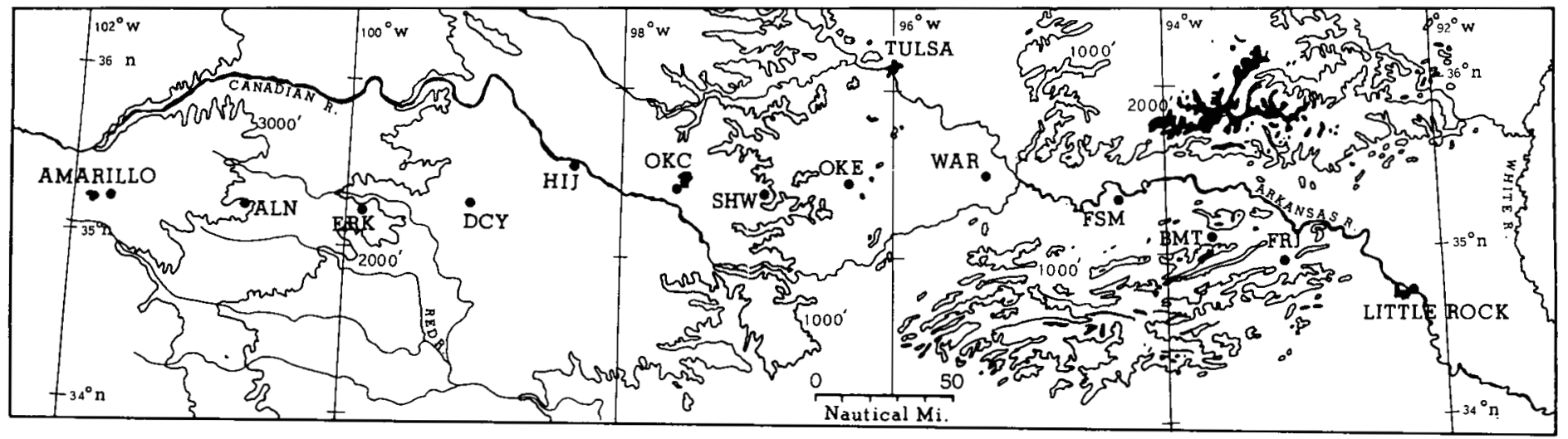

FIGURE 1.-The special Weather Bureau boundary-layer-jet research pibal observational line. Station identification code is listed in table 1 .

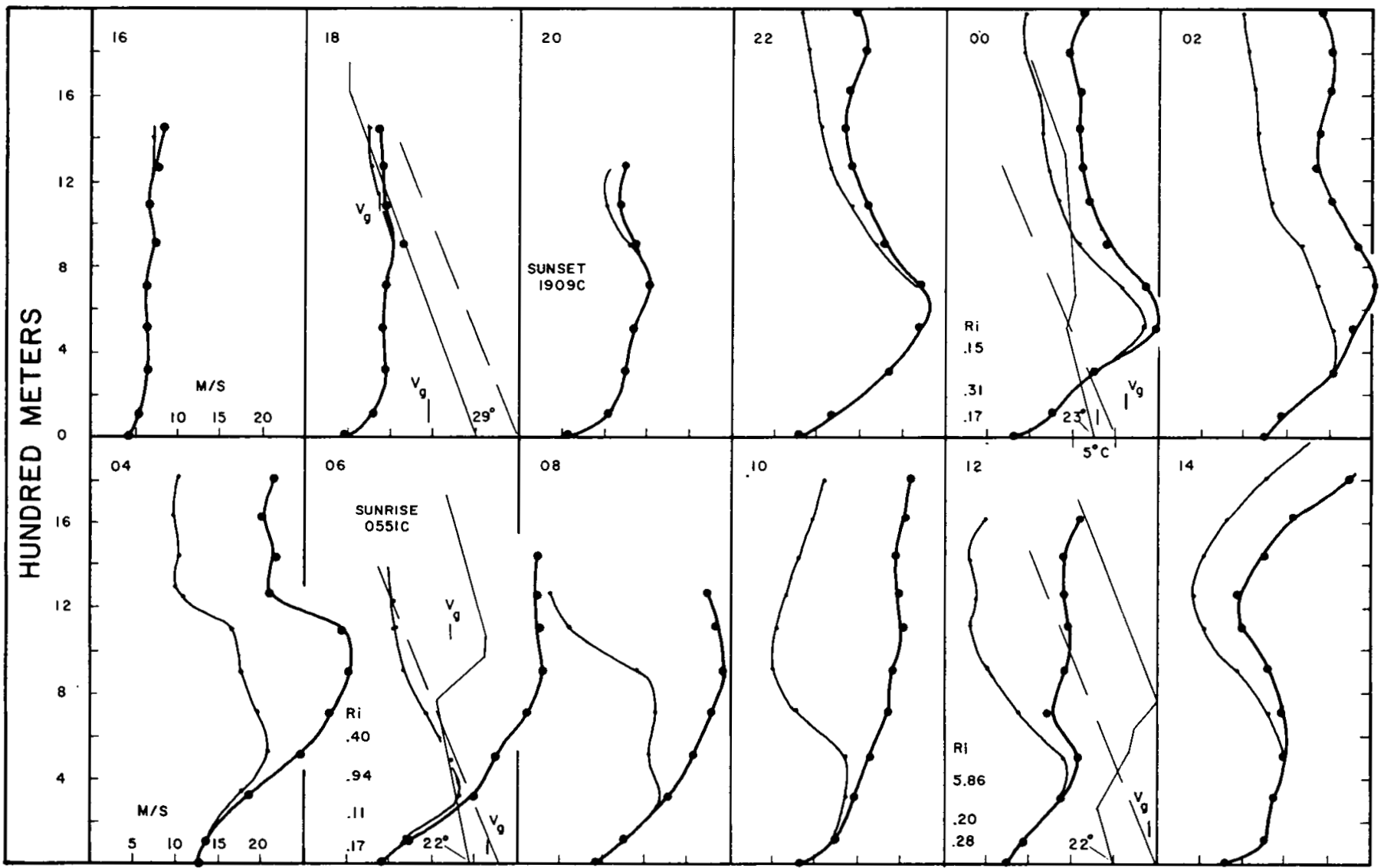

FigURE 2.-Height vs. speed graphs for the boundary-layer jet for 1600 cST, April 22 to 1400 csT, April 23, $1961 . \quad$ The thick curves represent the total wind speed while the thin lines show the southerly component speed. The vertical temperature structure is shown at synoptic times and the surface temperature $\left({ }^{\circ} \mathrm{C}\right.$.) is indicated near the bottom of the temperature sounding line; the wind speed scale also serves as the temperature scale with $5^{\circ} \mathrm{C}$. per interval. The dashed thin line shows the slope of constant potential temperature. The short vertical lines near the symbols $V_{g}$ show the sea level and $850-\mathrm{mb}$. geostrophic wind speed.

At the outset the reader is to note that surface winds are observers' estimates since the observational facility did not provide surface wind equipment. The magnitudes of the sea level and $850-\mathrm{mb}$. geostrophic wind vectors are shown at synoptic map times and are labeled as $V_{g}$; the vertical thermal structure for Oklahoma City ${ }^{1}$ is shown

1 The 0000 and 1200 cST observations actually came from Tinker AFB, a few miles from the Weather Bureau release point. at $1800,0000,0600$, and $1200 \mathrm{cs}$. Sunrise and sunset times are also shown. Referring to figure 2, which begins at $1600 \mathrm{CST}$, one sees the development of a jet-like profile as time proceeded into the hours of darkness. The jet profile of the total wind disappeared after 0400 CST on the $23 \mathrm{~d}$, but the southerly-component profile retained the shape of a jet throughout the period. In the hours between 0200 and 0600 CST the southerly-component jet 


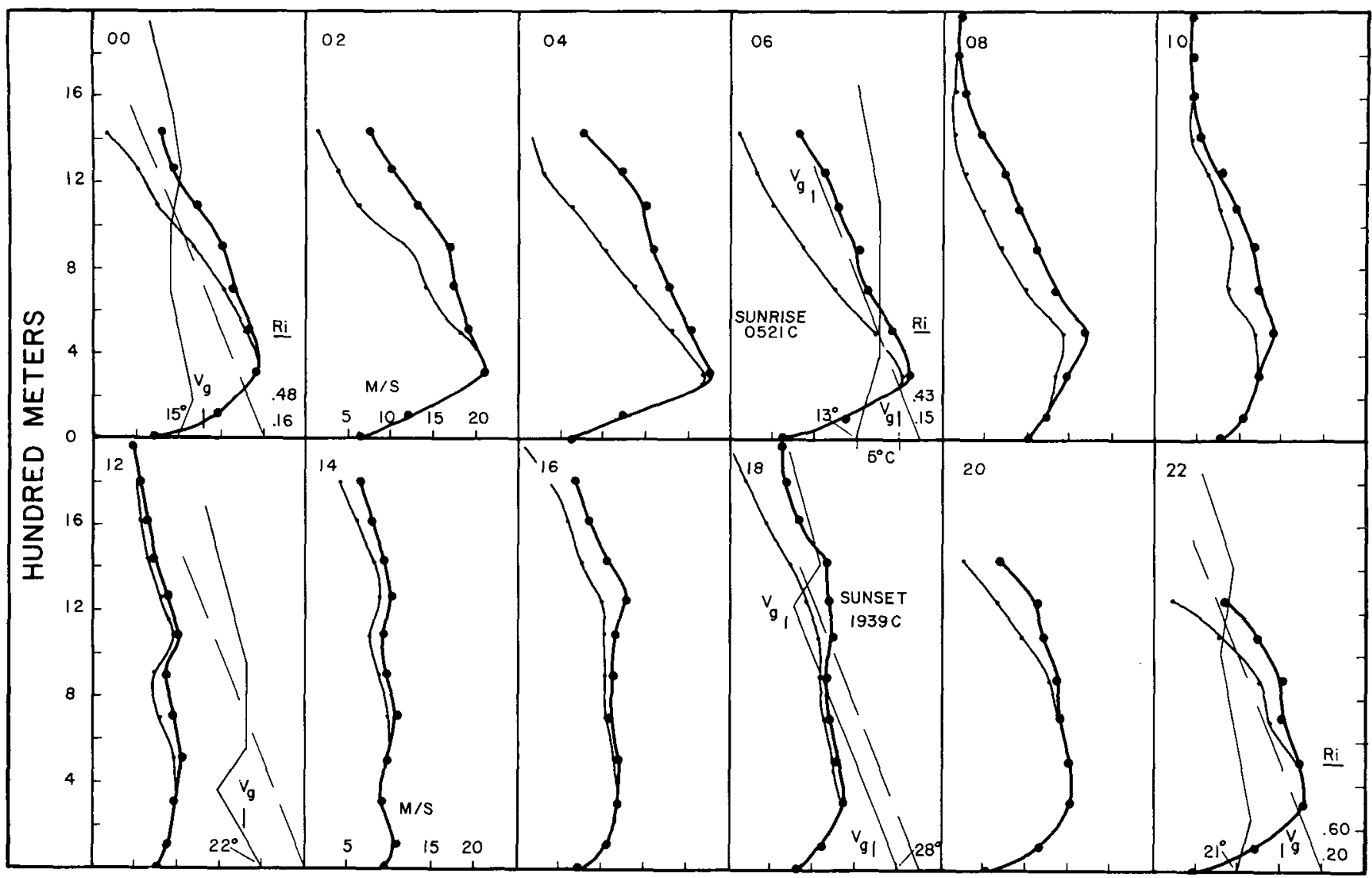

Figure 3.-Height vs. speed graphs for the boundary-layer jet for $0000 \mathrm{csT}$ to $2200 \mathrm{CST}$, May 28 , 1961 . For details, see legend for figure 2.

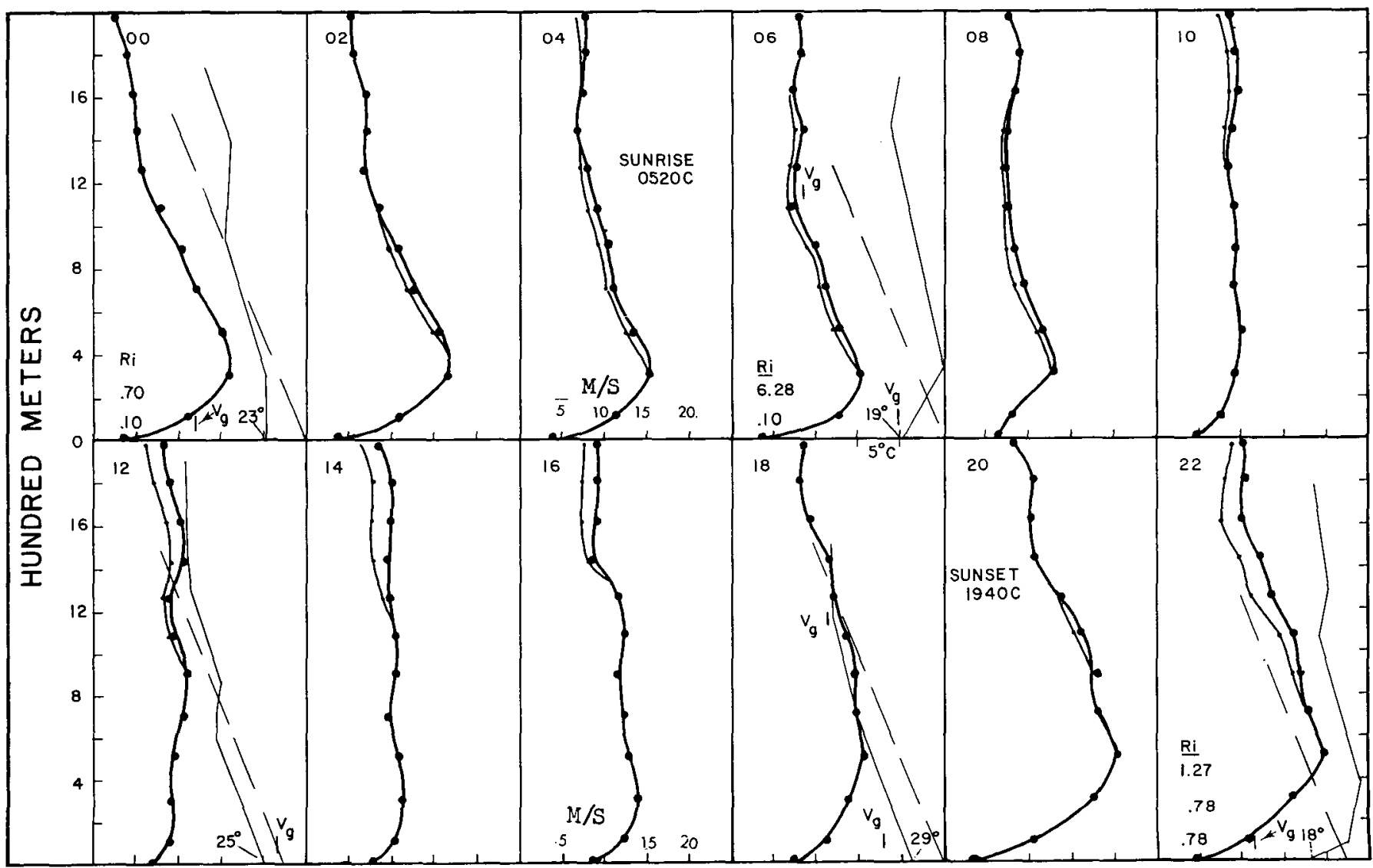

FIGURe 4.-Height vs. speed graphs for the boundary-layer jet for $0000 \mathrm{CST}$ to $2200 \mathrm{css}$, May 30, 1961 . For details, see legend for figure 2. $763-175-65-2$ 


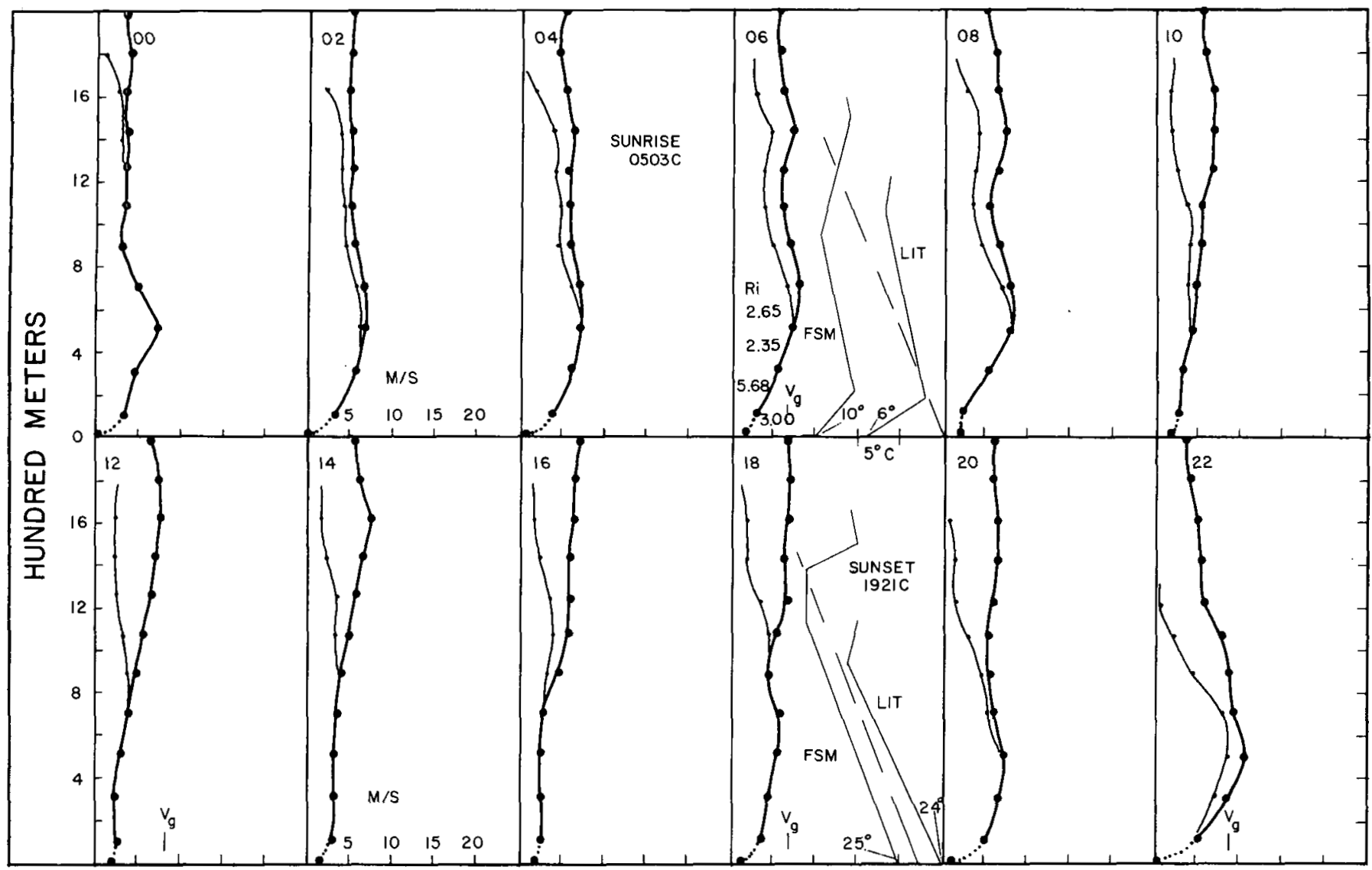

FIGURe 5.-Height vs. speed graphs for the boundary-layer jet for 0000 CsT to 2200 cst, May 28, 1961, for the "Rough Terrain" portion of the jet-research pibal line. For details, see legend for figure 2.

nose was much lower in elevation than the total-wind jet nose. The height of neither the total nor the southerlycomponent jet nose seemed to have any spatial relationship with the thermal stratification. It is worthy of mention, however, that a jet system did form even though lapse conditions prevailed from the ground upward to varying heights. A jet during lapse conditions was also observed by Smith and Wolf [8].

\section{MAY 28, 1961}

Figure 3 shows the wind-speed graphs for the period 0000 to 2200 cst, May 28, 1961. A basic difference between this observation and that for April was the formation of the nocturnal surface inversion. Such inversions have the effect of considerably decreasing surface friction. In this observation, the southerlycomponent and total-wind jet noses were sharper than in the April case. This is to be expected with surfacelayer stability. The separation in speed of the total and southerly components above about $250 \mathrm{~m}$., up to 1000 CST, was smaller in magnitude than for the April case. From 1200 through 1600 csT when turbulent exchange was high, speed separation was minimal. Again there was little apparent relationship between the height of the jet nose and thermal stratification. The maximum real wind speed in the boundary layer was subgeostrophic at 1200 and $1800 \mathrm{csT}$, and considerably supergeostrophic at 0000 and 2200 CST.

\section{MAY 30, 1961}

Figure 4 shows the wind speed versus height for the period 0000 to 2200 cst, May 30, 1961. This case, like May 28, had the nocturnal surface inversion. The period began with a strong jet profile that lasted through 0800 csT. The jet was somewhat supergeostrophic at 0000 CST on the 30 th, but subgeostrophic at 0600 CST since the geostrophic wind increased in the period. The jet wes again evident by 1800 csT and was strongly supergeostrophic at 2200 csT, partly because the geostrophic wind decreased markedly after $1200 \mathrm{CST}$. The jet nose remained near $300 \mathrm{~m}$. elevation for the early part of the day but formed and remained at $500 \mathrm{~m}$. in the evening hours. The nose was just at the top of the stable layer at $0000 \mathrm{CST}$ on the $30 \mathrm{th}$, but was above the stable layer at 2200 CST. Note the strong retardation of the real wind at 1200 CST. The difference between the total and southerly-component wind was much less than for either of the other observational periods. For the three observations considered here, the jet system was more pronounced and lower in elevation on those nights with surface inversions than it was on the night with lapse conditions in the lowest few hundred meters.

The times of Oklahoma City sunset and sunrise have been given in these figures to show that these jet systems can begin forming before sunset and can continue well past sunrise. 


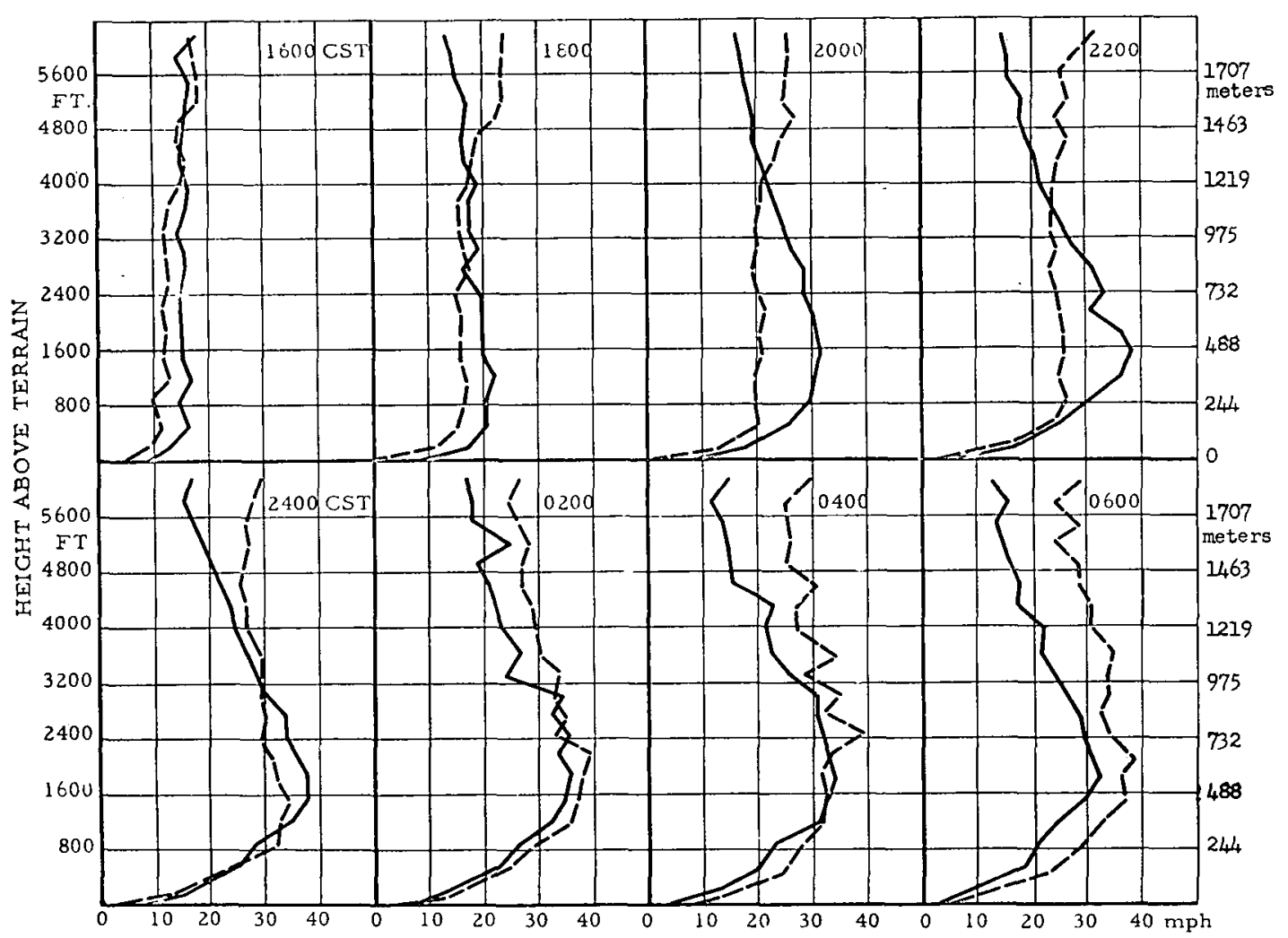

Figure 6.--Mean wind profiles for lapse (solid line) and inversion (dashed line) conditions for a region south of Fort Worth, Tex. and about 250 miles directly south of the Weather Bureau research pibal line. (From Smith and Wolf [8]).

\section{MAY 28, 1961, ROUGH TERRAIN}

There has been a minimum of investigation of the boundary-layer jet for areas other than the Great Plains. Since the Weather Bureau Special Pibal Line extended eastward into hilly and mountainous country, it was thought appropriate to compare the jet reaction there to that over the Plains. To assess this effect the wind speed distributions of the four stations from Little Rock to Fort Smith inclusive are presented in figure 5. Wind speeds averaged much less than for the center of the line, but a verage pressure gradients were likewise smaller on the eastern third of the line. However, the boundary-layer jet, though weaker, reacted in much the same manner as it did in the center of the line. The jet nose ranged from 500 to $700 \mathrm{~m}$. above the level of the ground, somewhat higher than for the center of the line for the same period. It is suggested that the roughness characteristics of the eastern portion of the line lifted the elevation of the jet speed maximum because of increased frictional drag with the ground.

Figure 6 shows, for comparison, profiles of space-averaged speed (13 stations) versus height for two boundarylayer wind jets in an area between Fort Worth and Fort Hood, Tex., from a study by Smith and Wolf [s]. Their results are rather difficult to compare with those of the Weather Bureau investigation since the authors gave geostrophic wind values as averages over the period of observation. Maximum speeds were not as high, how- ever, suggesting weaker pressure gradients. In figure 6 , the jet nose formed at about $500 \mathrm{~m}$. elevation for the lapse case (their test 3) and $250 \mathrm{~m}$. for the inversion case (their test 8 ) but both lifted to near $600 \mathrm{~m}$. by $0600 \mathrm{LST}$. There was not the marked difference in wind speed profiles between stable and unstable cases as noted in the Weather Bureau study. Nevertheless, their results were generally similar to those of this study even though their observational area was about $210 \mathrm{mi}$. south of the Weather Bureau pibal line.

\section{VARIATION OF VECTOR VERTICAL WIND SHEAR AND RICHARDSON NUMBERS}

Vertical wind shear was examined for the three observational periods particularly during the stabilizing hours of darkness. Comparison of the amount of vertical shear supported by the atmosphere in the Oklahoma City area was made with that of a similar study by Smith and Wolf [8], mentioned earlier. Richardson numbers are compared with those found in [8] and other studies. Shear was computed over relatively large height differences so the values probably are not as large as they might have been using smaller height intervals. Values of vertical shear are shown in table 2 for height intervals below the jet nose. As expected, shear values decreased with height for the inversion cases, and averaged greater for the inversion cases (May 28 and 30) than for the lapse case. They were lower for the rough terrain area. 
TABLE 2.-Comparison of Richardson number (Ri) and shear values (in units of sec. ${ }^{-1} \times 10^{3}$ )

\begin{tabular}{|c|c|c|c|c|c|c|c|c|c|c|c|c|}
\hline \multirow{2}{*}{ Level (meters) } & \multicolumn{2}{|c|}{$0000 \operatorname{cst}$} & \multicolumn{2}{|c|}{$0600 \mathrm{CsT}$} & \multicolumn{2}{|c|}{$1200 \mathrm{cst}$} & \multicolumn{2}{|c|}{$2200 \mathrm{CST}$} & \multicolumn{2}{|c|}{ Average } & \multirow{2}{*}{$\begin{array}{l}\text { Overall } \\
\text { average } \\
\text { Shear }\end{array}$} & \multirow{2}{*}{$\begin{array}{l}\text { Overall } \\
\text { average } \\
\qquad R i\end{array}$} \\
\hline & Shear & $R i$ & Shear & $R i$ & Shear & $R i$ & Shear & $R i$ & Shear & $R i$ & & \\
\hline & \multicolumn{10}{|c|}{ April 23, 1961 Smooth Terrain } & \multirow{6}{*}{42.7} & \multirow{6}{*}{${ }^{*} 0.35$} \\
\hline \multirow[t]{2}{*}{$\begin{array}{l}315-513 \\
0-315\end{array}$} & $\begin{array}{l}25 \\
42\end{array}$ & $\begin{array}{r}0.31 \\
.17\end{array}$ & $\begin{array}{l}45 \\
29\end{array}$ & $\begin{array}{r}0.11 \\
.17\end{array}$ & $\begin{array}{l}23 \\
19\end{array}$ & $\begin{array}{r}0.20 \\
.28\end{array}$ & & & 30.5 & 0.21 & & \\
\hline & \multicolumn{10}{|c|}{ May 28, 1961 Smooth Terrain } & & \\
\hline \multirow[t]{2}{*}{$\begin{array}{l}315-513 \\
0-315\end{array}$} & $\begin{array}{l}26 \\
66\end{array}$ & $\begin{array}{l}.48 \\
.16\end{array}$ & $\begin{array}{l}38 \\
74\end{array}$ & $\begin{array}{l}.43 \\
.15\end{array}$ & & & $\begin{array}{l}18 \\
59\end{array}$ & $\begin{array}{l}.60 \\
.20\end{array}$ & 46.8 & 0.34 & & \\
\hline & \multicolumn{10}{|c|}{ May 30, 1961 Smooth Terrain } & & \\
\hline \multirow[t]{2}{*}{$\begin{array}{l}315-513 \ldots \\
0-315\end{array}$} & $\begin{array}{l}25 \\
76\end{array}$ & $\begin{array}{l}.70 \\
.10\end{array}$ & $\begin{array}{l}28 \\
95\end{array}$ & $\begin{array}{r}6.28 \\
.10\end{array}$ & & & $\begin{array}{l}25 \\
56\end{array}$ & .78 & \}$^{50.8}$ & $\begin{array}{l}1.46 \\
*(.49)\end{array}$ & & \\
\hline & \multicolumn{10}{|c|}{ Nay 28,1961 Rough Terrain** } & & \\
\hline $\begin{array}{l}315-513 \ldots \\
0-315\end{array}$ & & & $\begin{array}{l}20 \\
28\end{array}$ & $\begin{array}{l}5.68 \\
3.00\end{array}$ & & & & & 24.0 & 4.34 & 24.0 & 4.34 \\
\hline
\end{tabular}

- Excludes large $R i(6.28)$ at 0600 cst May 39.

Comparison of shear values from Weather Bureau data with those reported by Smith and Wolf [S] for similar terrain was not equitable since they used smaller height intervals and did not report the geostrophic wind at specific times. However, table 3 compares their lowest two levels with the Weather Bureau lowest level for maximum nighttime values in both lapse and inversion conditions. Shear values averaged higher for inversion conditions for [8] but the Weather Bureau data had greater separation for the values between lapse and inversion conditions.

Richardson numbers were computed from

$$
R i=\frac{(g / \theta)(d \theta / d z)}{(d u / d z)^{2}}
$$

where RAOB data were available, for comparison between lapse and inversion conditions and for smooth and rough terrain. Values are shown in figures $2,3,4$, and 5 , in the height intervals they represent and also in table 2 . 'Table 2 shows that Richardson numbers averaged lower over smooth terrain but not lower in inversion conditions as compared to lapse conditions. However, the lowest value, 0.10 , did occur under inversion conditions at 0000 CsT, May 30. Smaller values of $d \theta / d z$ in the numerator of equation (1) explain the lower Richardson numbers for the lapse case.

Much work has been done in trying to find a critical

TА BLE 3.-Comparison of maximum nighttime shear values (units are sec. $\left..^{-1} \times 10^{3}\right)$

\begin{tabular}{|c|c|c|c|c|}
\hline & Weather & \multicolumn{3}{|c|}{ Smith and Wclf $[8]$} \\
\hline & $0-354 \mathrm{ft}$. & $8-180 \mathrm{tt}$. & $180-540 \mathrm{ft}$. & A verage \\
\hline $\begin{array}{l}\text { Lapse Conditions } \\
\text { Inversion Conditions }\end{array}$ & $\begin{array}{l}42 \\
95\end{array}$ & $\begin{array}{l}81 \\
91\end{array}$ & $\begin{array}{l}45 \\
57\end{array}$ & $\begin{array}{l}€ 3 \\
74\end{array}$ \\
\hline
\end{tabular}

Richardson number that will predict the beginning of turbulence in stable boundary layers. The most generally accepted value is 0.25 for low levels although values as low as $1 / 25$ have been observed very close to the ground [3]. Since Richardson numbers from the Weather Bureau data go below 0.25 (table 2), there was probably turbulence in the inversion as well as in the lapse layers of the boundary-layer jet systems described here. The investigation [8] of low-level jets in north-central Texas, mentioned earlier, gave much higher Richardson numbers for inversion conditions but for the lapse condition late at night [8] provided numbers very close to those for the Weather Bureau lapse condition.

\section{TIME VARIATION OF VECTOR WIND RELATED TO THE GEOSTROPHIC WIND}

The boundary-layer wind undergoes diurnal speed and directional variations as a result of the diurnal variation of frictional coupling of the wind with the ground. The forces involved are shown in equation (2).

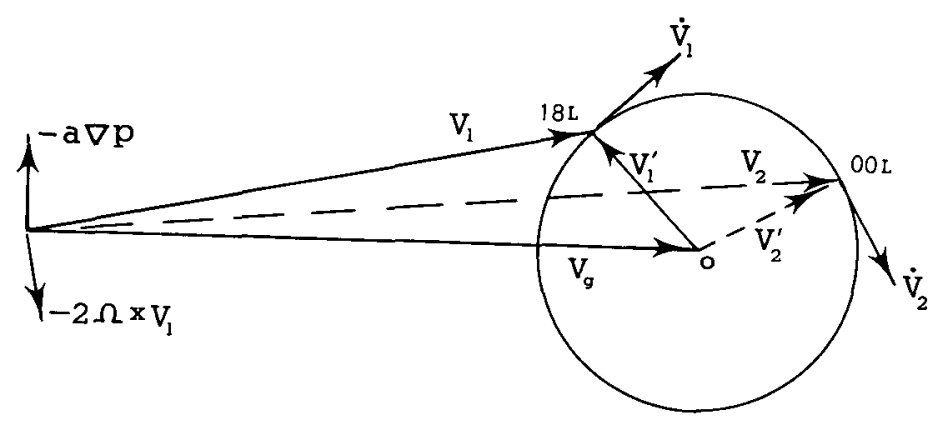

FigURE 7.- Schematic representation of the effect of the incrtial oscillation on the real wind in the boundary layer. $\dot{\mathbf{v}}$ is the rotating acceleration vector and $\mathbf{V}^{\prime}$ is the geostrophic departure vector. Typical alignments of the roal wind vector at $1800 \mathrm{LST}$ and 0000 LST are shown. 

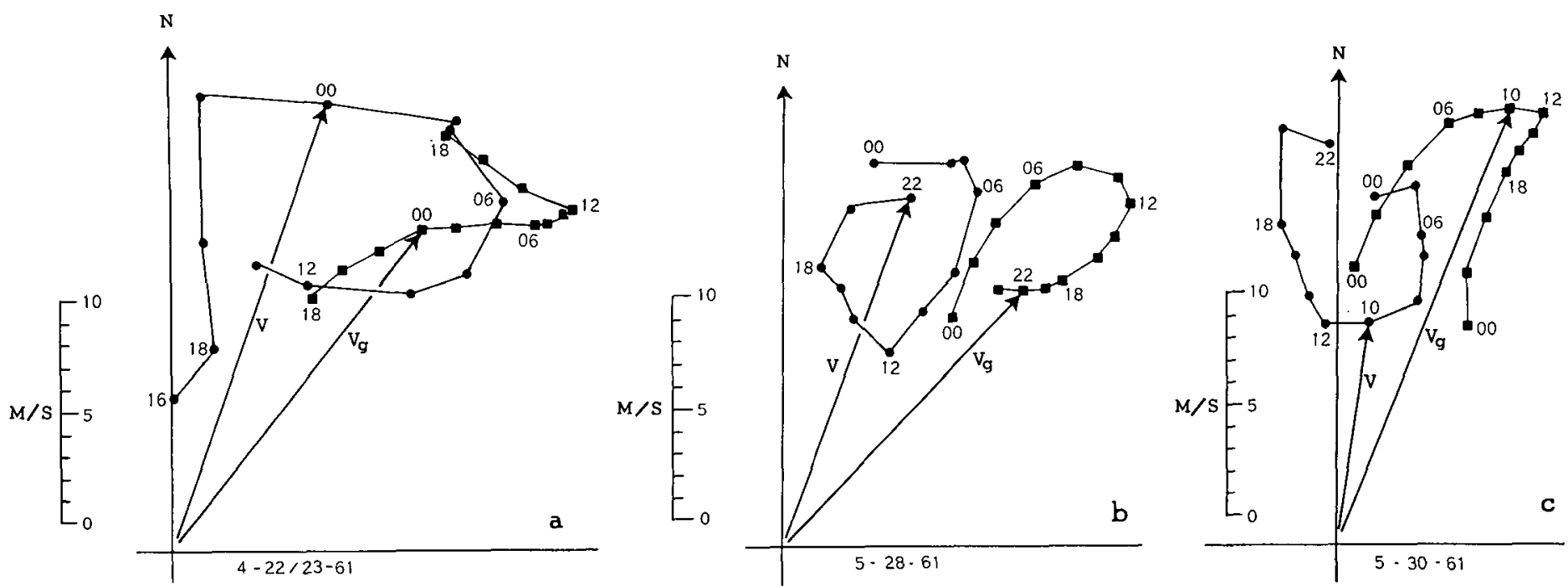

FIgURE 8.-Time variation of real vector wind averaged at 315,513 , and $706 \mathrm{~m}$. elevation and the coincident variation of the sea level vector geostrophic wind for April 22-23, May 28, and May 30, respectively.

$$
\dot{\mathbf{V}}=-\alpha \nabla p-2 \Omega \times \mathbf{V}+\alpha \mathbf{F}
$$

During a part of the afternoon the terms on the right are in quasibalance, and the boundary-layer wind does not accelerate. When friction decreases in the late afternoon and evening, the terms of the equation become unbalanced and the real wind accelerates in a direction shown by the vector $\dot{\mathbf{v}}$ in figure 7 . It then may undergo an inertial oscillation with a period of about one day and the real wind may become supergeostrophic some time during the night. The process is treated theoretically by Blackadar [1] and Buajitti and Blackadar [4].

Vector winds from the Weather Bureau research pibal line were averaged at 315,513 , and $706 \mathrm{~m}$. above the ground for each observational period and plotted on polar diagrams serially in time. Figure 8 shows the fairly regular clockwise oscillations of the real wind which occurred in approximately the inertial period. That such regular oscillations appear in single cases, as opposed to averaged cases, seems rather remarkable. Shown also are the coincident variations of the sea level geostrophic wind. Note that linear acceleration predominated from early afternoon until 2000 to 2200 CST on April 22 (fig. 8a) and May 30 (fig. 8c), and predominantly clockwise turning of the wind vectors occurred from then until about 0400 cST. Smith and Wolf [8] suggest that this modification of the inertial oscillation is caused by the release of friction late in the afternoon, as convective turbulence subsides, and later by the beginning of internal turbulence friction about 2000 to 2200 CST when critical shear in the boundary layer is reached. As soon as the internal turbulent friction halts the linear acceleration, and provided the real wind is supergeostrophic, the relatively large Coriolis force of the real wind dominates the pressure gradient force and turns the real wind to the right and eventually upgradient. The typical varia-

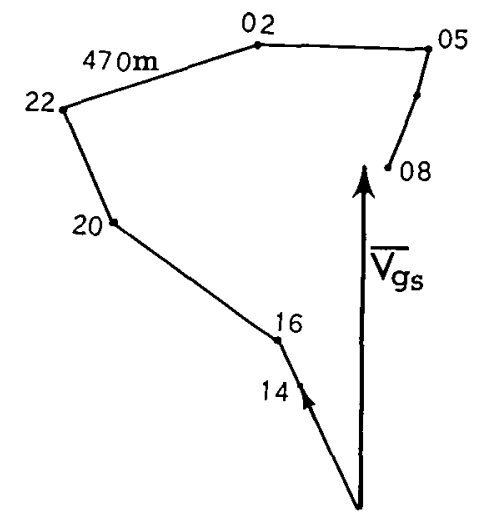

Frgure 9.-Schematic time variation of $470-\mathrm{m}$. wind for the region south of Fort Worth, Tex. Numbers at data points are time (CsT). (From Smith and Wolf [8]).

tion of the real wind found in the Texas study [8] is shown in figure 9.

A preliminary comparison of the observed vector wind changes of figure 8 , to the vector changes computed from

$$
\mathbf{V}_{2}-\mathbf{V}_{1}=f\left(\mathbf{V}-\mathbf{V}_{g}\right) \times \mathbf{k}
$$

using the Weather Bureau data shows that the observed wind usually did not change in the exact direction and magnitude indicated by equation (3), although there was usually a component of the computed change in the direction of the real change. A time difference of $1 \mathrm{hr}$. was used. This suggests that the geostrophic wind shown here (fig. 8) was not always the true geostrophic wind even though it was determined from a careful analysis of synoptic maps. Deviations between the computed and actual wind vector changes were particularly large in the late morning hours and at night from about 2000 to 0400 CST. 

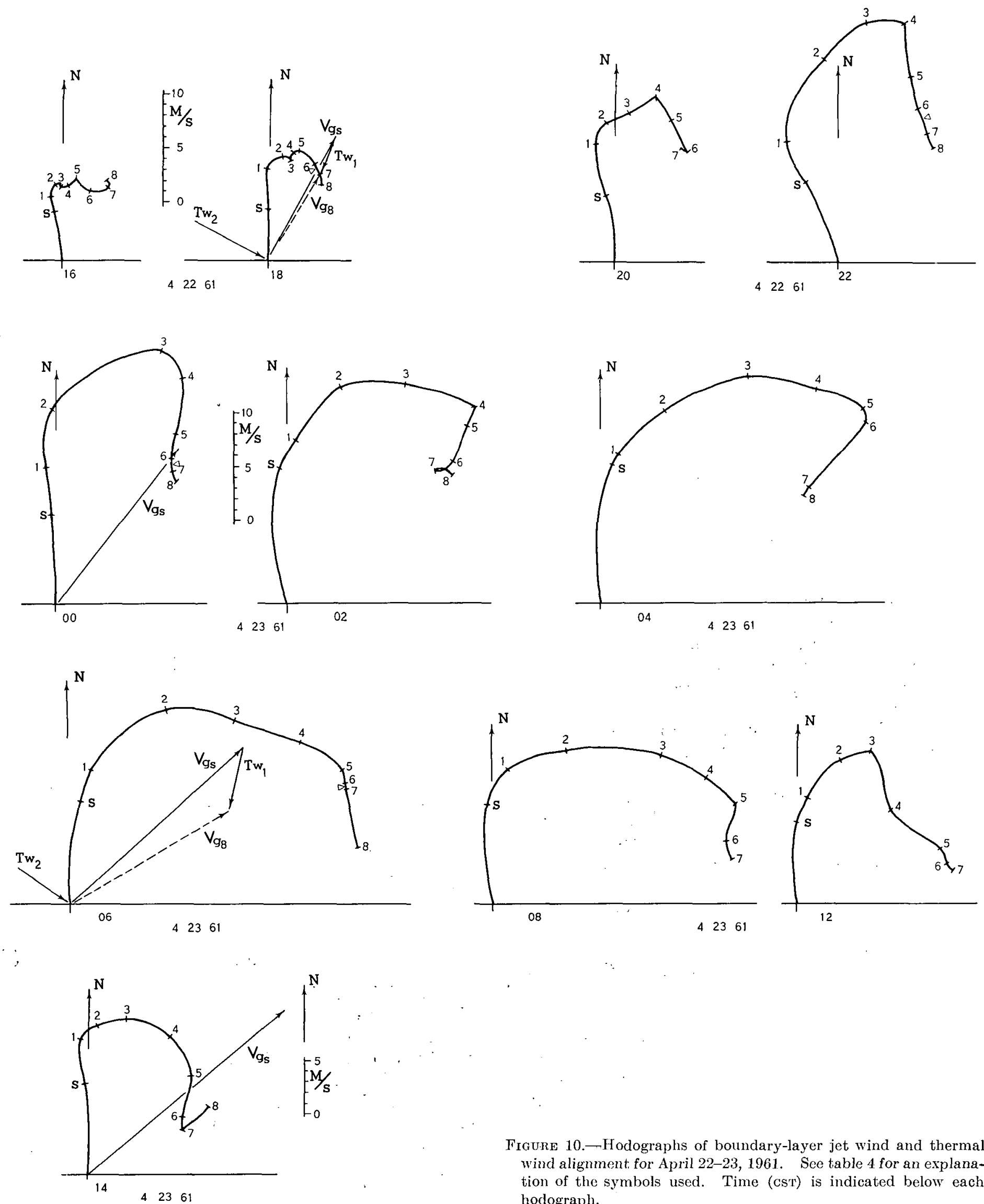

Figure 10.-Hodographs of boundary-layer jet wind and thermal wind alignment, for April 22-23, 1961. See table 4 for an explanation of the symbols used. Time ( $\mathrm{CS}^{\mathrm{T}}$ ) is indicated below each hodograph. 

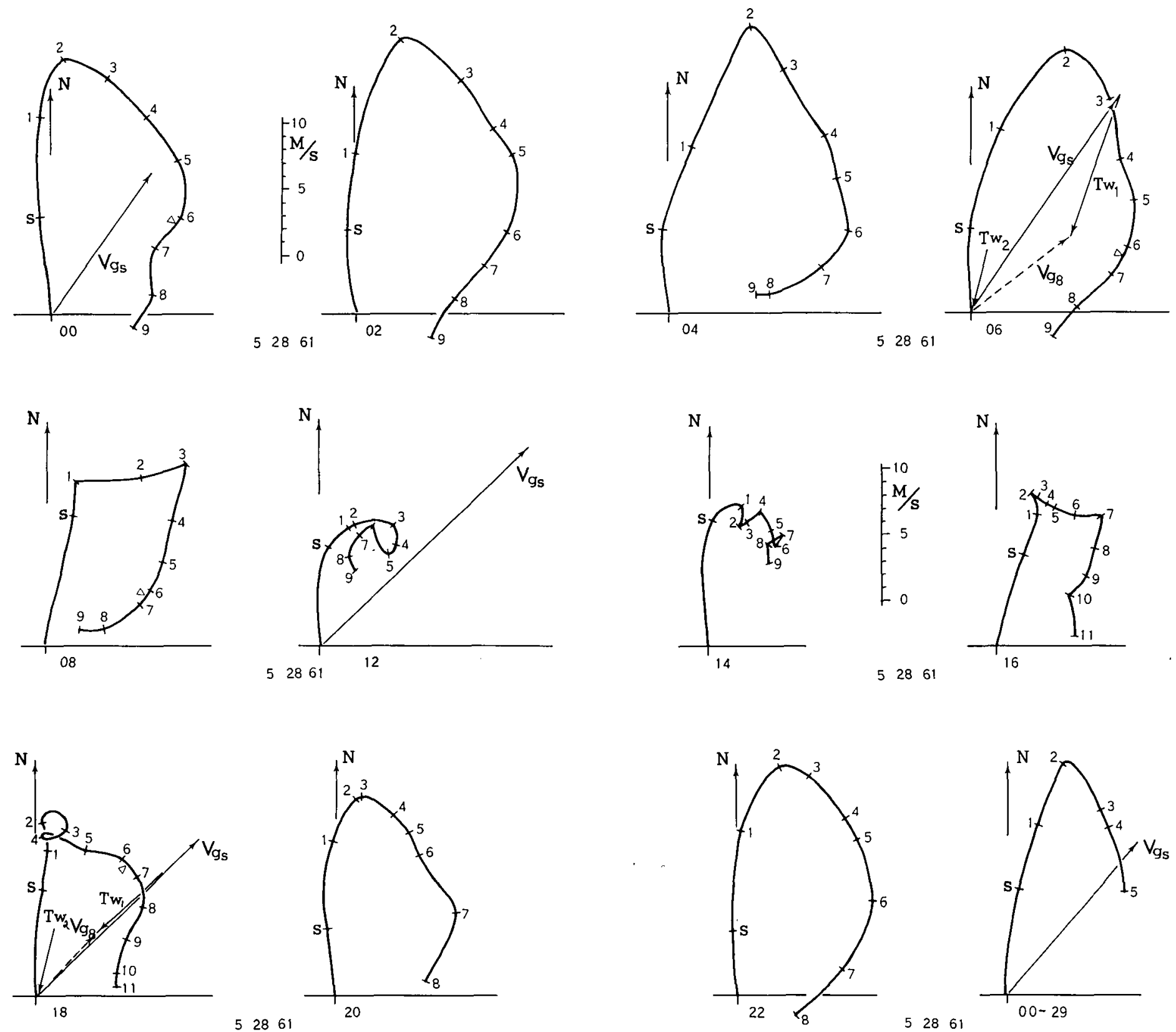

Figure 11.- Hodographs of boundary-layer jet wind and thermal wind alignment for May 28, 1961 . See table 4 for an explanation of the symbols used. Time $(\operatorname{Cs} T)$ is indicated below each hodograph.

The reader's attention is directed to the fact that, in general, the time derivatives of the real and geostrophic wind vectors in figure 8 were approximately $180^{\circ}$ out of phase.

\section{LOW-LEVEL JET HODOGRAPHS AND THE THERMAL WIND}

Useful information about the vertical structure of a vector wind field can be had from plots of vertical shear analyzed on a polar diagram. The boundary-layer jet systems observed by the Weather Bureau Special Pibal Line in 1961 were studed by this method. Comparisons
TaBLE 4.-Conventions used in hodographs of figures 10,11, and 12

\begin{tabular}{|c|c|c|}
\hline Level & $\begin{array}{c}\text { Height } \\
\text { alove ground } \\
\text { (meters) }\end{array}$ & Symbols \\
\hline $\begin{array}{l}\mathrm{S}_{\mathrm{N}} \\
1 \\
\mathbf{2} \\
\mathbf{3}\end{array}$ & $\begin{array}{r}\text { Surface } \\
108 \\
315 \\
513 \\
706 \\
\mathbf{8 9 5} \\
1,080 \\
1,260 \\
1,440 \\
1,620 \\
1,800 \\
1,980\end{array}$ & 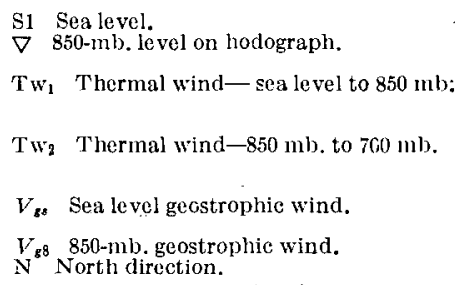 \\
\hline
\end{tabular}



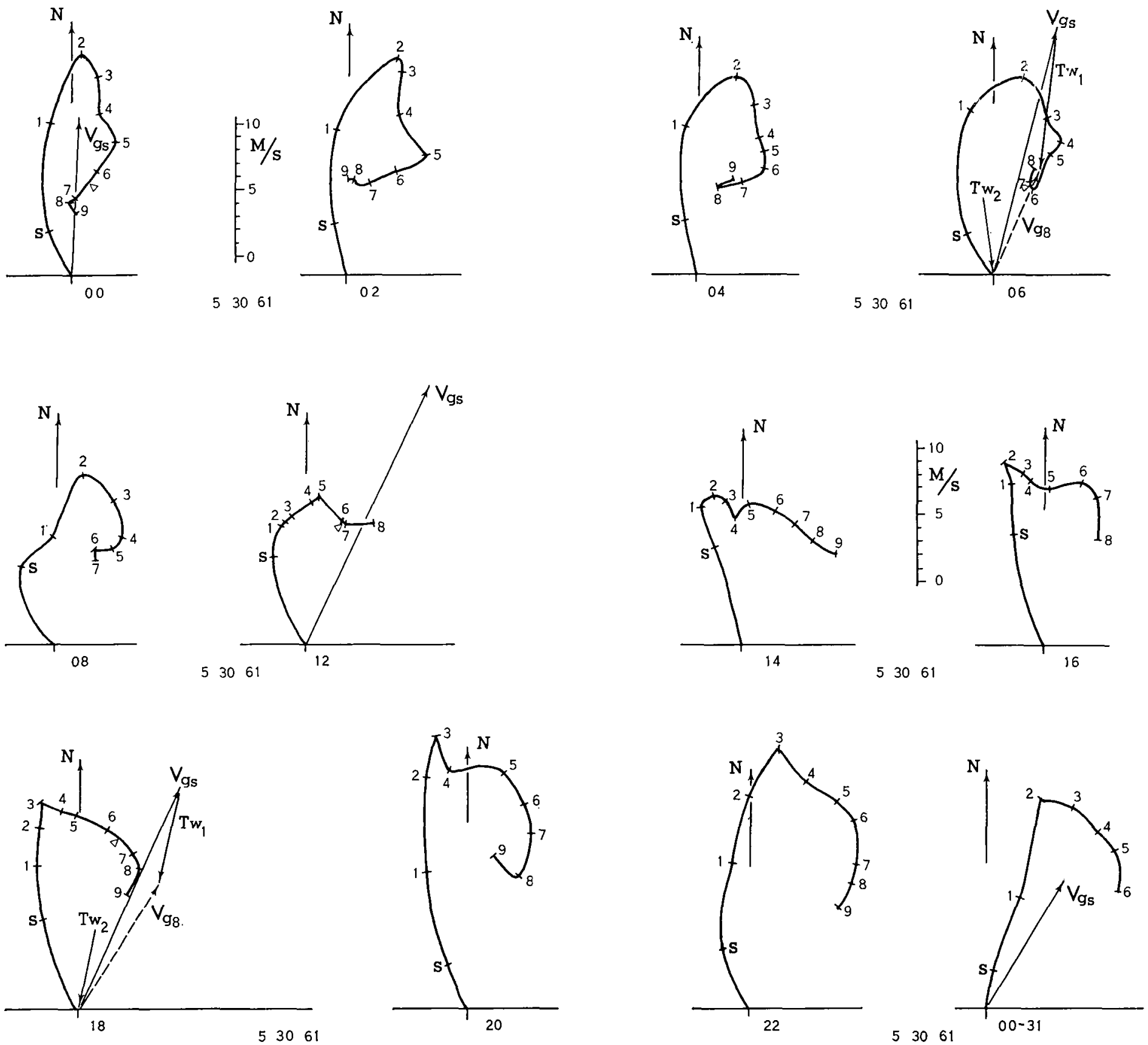

Frgore 12.- Hodographs of boundary-layer jet wind and thermal wind alignment for May 30,1961 . See table 4 for an explanation of the symbols used. Time ( $\operatorname{Cs} T)$ is indicated beneath each hodograph.

were made between these jet systems, and with the Ekman Spiral and other theoretical distributions [2] of boundary-layer winds.

Figures 10, 11, and 12 show vector shear plots, or hodographs, at 2-hr. intervals, of the averaged winds (5 central stations) for the three jet systems considered in this paper. Table 4 shows the height- and vector-symbol conventions used in these hodographs. In the figures, notice the decrease of geostrophic wind speed with height at 0600 and $1800 \mathrm{CST}$, particularly marked in the two May cases. This distribution of the geostrophic wind in the vertical sharpens the nose of the low-level jet. The existence of the sharp speed cutback above the level of maximum speed after nearly unidirectional speed increase from the surface up to $315 \mathrm{~m}$. (level 2 in the figs.), during darkness, is mutually charac teristic of the two nocturnal inversion cases in May. The case of April 22-23, however, is quite different. At the beginning of the period, $1600 \mathrm{csT}$, April 22, the boundary-layer wind speed was very low but as night came on, the speed at all levels increased markedly and the turning to westerly directions at the higher elevations continued until $0600 \mathrm{CST}$, on the $23 \mathrm{~d}$. 

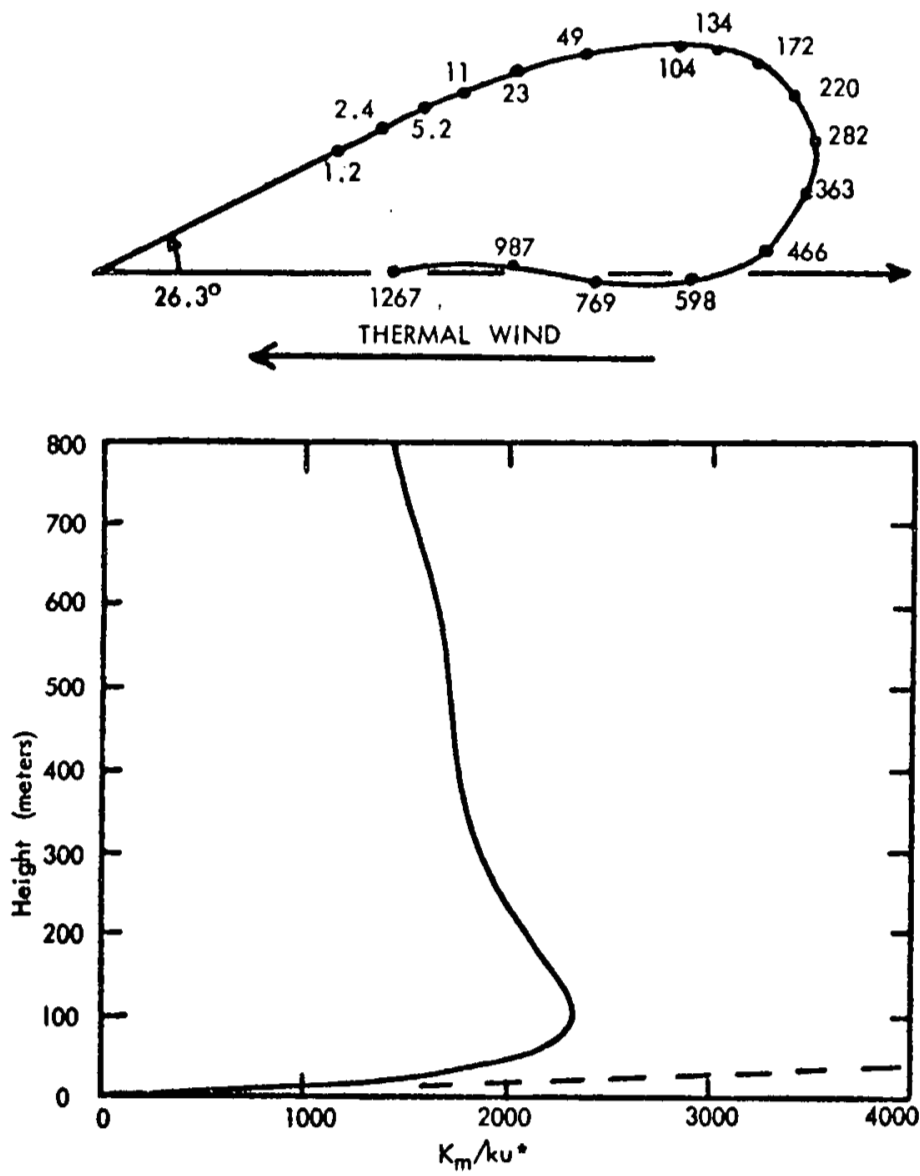

Figure 13.- Theoretical boundary-layer wind hodograph and vertical distribution of exchange coefficient; thermal wind opposed to the surface geostrophic wind. (From Blackadar [2].) Note the similarity to hodographs in figures 11 and 12 .

The speed increase was consistent with the increase of $V_{g}$ both at sea level and at $850 \mathrm{mb}$. This observation had no nocturnal surface inversion. One can easily see from a comparison of just the hodographs that the case of April 22-23 was of a different type from the two May cases.

With certain assumptions, the theoretical boundarylayer wind distribution with height is the Ekman spiral. The wind distributions studied here hardly resemble the Ekman spiral except perhaps that of May 28 at noon. It was noticed, however, that the nocturnal hodographs of the low-level jets for May 28 and 30 strongly resemble a theoretical hodograph developed by Blackadar [2], in which the thermal wind opposes the geostrophic wind. The theoretical hodograph is shown in figure 13 along with the specified height variation of exchange coefficient. Note that not only is the elevation of the nose of Blackadar's theoretical jet nearly the same as the noses of the May 28 and 30 jets but the geometric similarity of the nocturnal hodographs to his model is remarkable. A geostrophic thermal wind vector of relatively large magnitude (labeled $\mathrm{T}_{\mathrm{w}_{1}}$ ) for the sea level to $850-\mathrm{mb}$. interval ${ }^{2}$ in the two May cases, both at 0600 and 1800 CST, was

2 Vestor difference between sea level and $850-\mathrm{mb}$. geostrophic wind vectors. $763-175-65-3$

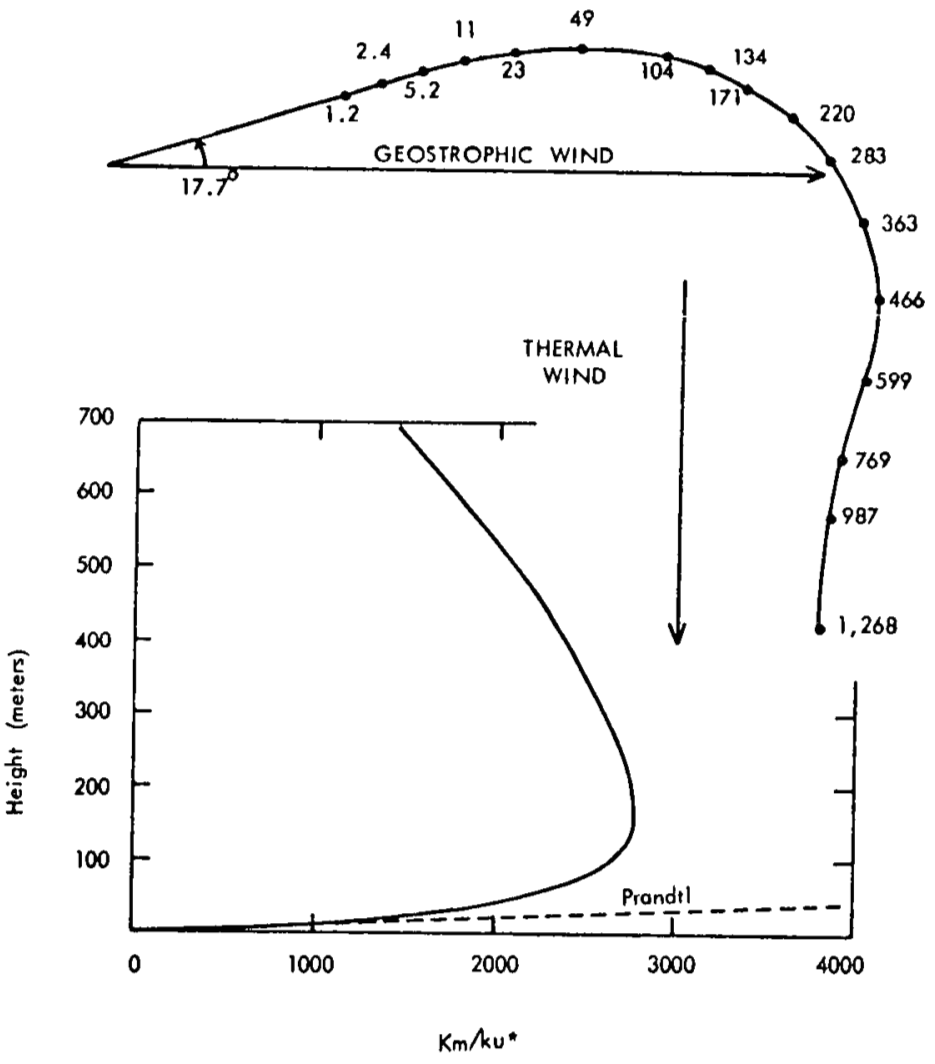

FigURE 14.--Theoretical boundary-layer wind hodograph and vertical distribution of exchange coefficient; thermal wind is $90^{\circ}$ to right of surface geostrophic wind. (From Blackadar [2].) Compare with hodographs in figure 10.

almost directly opposed to the sea level geostrophic wind vector (very much like the model by Blackadar in fig. 13); further, the thermal wind vector for the $850-$ to $700-\mathrm{mb}$. interval (labeled $\mathrm{Tw}_{2}$ ) was likewise opposed to the sea level greostrophic wind vector. The opposition of the sea level geostrophic and thermal wind vectors is indicative of a warm low pressure system in the region and since a warm pressure system is shallow, the geostrophic wind (as well as the real wind) should decrease with height. Such was the case for May 28 and 30 , but of course, the boundary-layer real wind was modified by the "inertial effect". An analysis of the layer thickness from 850 to $700 \mathrm{mb}$. along the special pibal line confirmed that indeed the air was warmer for a considerable distance to the west of the jet for both May cases at both 0600 and 1800 CST. The magnitudes of the thermal winds were estimated from (see Saucier [7])

$$
\Delta \mathbf{V}_{\mathrm{g}}=(980 / f) \cdot(\partial \Delta z / \partial n)
$$

where $(\partial \Delta z)$ is the height difference change between 700 and $850 \mathrm{mb}$., along the pibal observational line.

The observation of April 22-23 differed from those in May in the upper-level wind alignment, further emphasizing the difference between these two types of low-level jet systems. Here the upper-level thermal winds $\left(\mathrm{Tw}_{2}\right)$ were nearly at right angles (instead of parallel) to the sea level 
geostrophic wind, and the low-level thermal wind vectors were quite small. After $1800 \mathrm{csT}$, April 22, when the boundary-layer wind increased in speed, the speed maximum at about $400 \mathrm{~m}$. (between levels 2 and 3) veered and the hodograph pattern elongated to the east. This development was compatible with the alignment of the upper-level thermal wind during the period and was very much like Blackadar's [2] theoretical boundary-layer hodograph in figure 14 with a thermal wind at right angles to the sea level geostrophic wind.

The analysis of these hodographs suggests that if an adverse thermal wind exists at about $1800 \mathrm{CST}$ along with southerly low-level flow, and if the adverse thermal wind can be forecast to persist during the following hours of darkness, the boundary-layer jet system (speed maximum at about $300 \mathrm{~m}$. above the ground), similar to that found in the May cases, can be expected to occur that night. As mentioned earlier, the occurrence of the surface nocturnal inversion allows greatly increased low-level vertical shear which favors a higher jet speed for a given initial sea level pressure gradient.

\section{CONCLUDING REMARKS}

The boundary-layer wind jet generally appears to operate within certain simplified physical principles of meteorology. An exception (at least in this study) is its relationship with the geostrophic wind.

The meteorological variables that particularly favor the very low-level and sharp jet appear to be the opposing thermal wind vector and the nocturnal inversion, the latter following an afternoon of strong insolation.

Time-variations of the boundary-layer jet systems observed by the special Weather Bureau jet research network show similarities with two other serially-observed jet systems. Quantitative differences were not readily comparable because pressure gradient data for the other jet systems were not provided. Theoretical hodographs of boundary-layer winds with opposing and lateral thermal wind vectors developed by Blackadar [2] are strikingly similar to the Weather Bureau jet hodographs also having opposing and lateral thermal wind vectors.

Richardson numbers found in the shear layer below the jet nose for the time of jet speed maxima were generally less than 0.25 , which is the usually accepted critical value for the beginning of mild turbulence in the jet region.

The following meteorological conditions were extant [5] in the jet region during the period of the three jets examined in this study and since they are physically consistent with the formation of the jet they are considered optimal for its appearance. They are: (1) steady southerly wind flow; (2) cloudless night; (3) warm low-pressure area to the west; (4) lair east-to-west sea level pressure gradient; (5) strong afternoon insolation for the air flowing into the jet region; (6) no intruding fronts. Since these items are generally easy to forecast, interests for whom the nocturnal jet might be of annoyance should not have to be without a forewarning.

In future analyses some more conservative basis than the geostrophic wind for determining the degree of nonpressure-gradient acceleration of the real wind should be used, since the real wind in these individual cases showed no simple relationship with the geostrophic wind. It should be pointed out that for some of the instances presented here the large degree of supergeostrophic wind speed was made possible by the rapid decrease of the geostrophic wind speed during the growth of the jet. At other times the geostrophic wind speed increased at the same time as the jet and allowed only a small degree of supergeostrophic real wind speed. Essentially, the sea level geostrophic wind vector appeared to have a diurnal oscillation somewhat out of phase with the boundary-layer-jet wind vector.

\section{REFERENCES}

1. A. K. Blackadar, "Boundary Layer Wind Maxima and their Significance for the Growth of Nocturnal Inversions," Bulletin of the American Meteorological Society, vol. 38, No. 5, May 1957, pp. 283-290.

2. A. K. Blackadar, "The Vertical Distribution of Wind in a Baroclinic Adiabatic Atmospheric Boundary Layer," Presented at the 211th National Meeting of the AMS, Jan. 1963, Pennsylvania State University, University Park, Pa.

3. A. K. Blackadar et al., "Structure of Turbulence and Mean Wind Profiles within the Atmospheric Boundary Layer", Pennsylvania State University, Dept. of Meteorology, University Park, Pa. Final Report on Contract No. AF 19(604)-5231, Oct. 1960. (See pp. 61-63).

4. K. Buajitti and A. K. Blackadar, "Theoretical Studies of Diurnal Wind-Structure Variations in the Planetary Boundary Layer," Quarterly Journal of the Royal Meteorological Society, vol. 83, No. 358, Oct. 1957, pp. 486-500.

5. W. H. Hoecker, Jr., "Three Southerly Low-Level Jet Systems Delineated by the Weather Bureau Special Pibal Network of 1961," Monthly Weather Review, vol. 91, Nos. 10-12, Oct.Dec. 1963, pp. 573-582.

6. S. Petterssen, Weather Analysis and Forecasting, vol. I, McGrawHill Book Co., New York, N.Y., 1956, 428 pp. (See p. 61).

7. W. J. Saucier, Principles of Meteorological Analysis, The University of Chicago Press, Chicago, Ill., 1955, $438 \mathrm{pp}$.

8. T. B. Smith and M. A. Wolf, "Further Analysis of WINDSOC Data," Meteorology Research, Inc., Altadena, Calif. Final Report to U.S. Army Chemical Corps, Dugway Proving Ground, Contract DA-42-007-CML-504, Nov. 1961.

9. H. Wexler, "A Boundary Layer Interpretation of the Low-Level Jet," Tellus, vol. 13, No. 3, Aug. 1961, pp. 369-378.

[Received December 23, 1963; revised November 24, 1964] 